\title{
О ПРОЦЕДУРЕ ОЦЕНКИ СОСТОЯНИЯ И ПОСТАНОВКИ НАСАЖДЕНИЙ НА КАДАСТРОВЫЙ УЧЕТ
}

\section{Екатерина Алексеевна Васильева}

Сибирский государственный университет геосистем и технологий, 630108, Россия, г. Новосибирск, ул. Плахотного, 10, магистрант кафедры экологии и природопользования, тел. (383)361-08-86, e-mail: biomars217@gmail.com

\section{Ольга Николаевна Николаева}

Сибирский государственный университет геосистем и технологий, 630108, Россия, г. Новосибирск, ул. Плахотного, 10, профессор кафедры экологии и природопользования, тел. (383)361-08-86, e-mail: onixx76@mail.ru

\section{Людмила Константиновна Трубина}

Сибирский государственный университет геосистем и технологий, 630108, Россия, г. Новосибирск, ул. Плахотного, 10, доктор технических наук, профессор кафедры экологии и природопользования, тел. (383)361-08-86, e-mail: trubinalk@rambler.ru

В статье кратко описана проблематика рассмотрения городских зеленых насаждений (ГЗН) как неотъемлемой части земельного участка, относящегося к городской среде. Перечислены аргументы для создания единой актуализированной базы данных всех имеющихся ГЗН. Указаны основные виды нарушений ГЗН, возникающие в результате антропогенной деятельности. Охарактеризованы действующие методы в области инвентаризации и мониторинга состояния ГЗН. Отмечен вопрос недостаточной проработанности нормативно-правовой документации в сфере постановки ГЗН на учет в Единый государственный реестр объектов недвижимости (ЕГРН). Отмечено, что отсутствие подходов к рассмотрению ГЗН как самостоятельных кадастровых объектов влечет за собой многочисленные нарушения в сфере экологического и природоохранного законодательства населенных пунктов. Предложено решение этой проблемы, заключающееся в обязательном учете кадастровых данных о земельном участке под ГЗН при ведении базы данных мониторинга ГЗН. Представлена оценочная шкала для комплексной оценки состояния ГЗН, предварительный пример алгоритма постановки ГЗН на кадастровый учет и присвоение каждому индивидуального кадастрового номера.

Ключевые слова: городские зеленые насаждения, инвентаризация, мониторинг, объекты озеленения, подеревная инвентаризация, кадастровый учет, ГИС

\section{ON THE PROCEDURE FOR EVALUATING AND PLACING GREEN SPACES AND CADASTRAL REGISTRATION}

\section{Ekaterina A. Vasil'eva}

Siberian State University of Geosystems and Technologies, 10, Plakhotnogo St., Novosibirsk, 630108, Russia, Student, Department of Ecology and Environmental Management, phone: (383)361-06-86, e-mail: biomars217@gmail.com

\section{Olga N. Nikolaeva}

Siberian State University of Geosystems and Technologies, 10, Plakhotnogo St., Novosibirsk, 630108, Russia, D. Sc., Professor, The Department of Ecology and Natural Resources Management, phone: (383)361-08-86 


\section{Lyudmila K. Trubina}

Siberian State University of Geosystems and Technologies, 10, Plakhotnogo St., Novosibirsk, 630108, Russia, D. Sc., Professor, Department of Ecology and Environmental Management, phone: (383)361-06-86, e-mail: trubinalk@rambler.ru

The article briefly discusses the problem of considering urban green spaces as an integral part of a land plot related to the urban environment. The pros for creating a single updated database of all available urban green spaces are listed. The main types of violations of urban green spaces as a result of anthropogenic activities are indicated. The current methods in the field of inventory and monitoring of the state of the state health service are described. The issue of insufficient elaboration of regulatory and legal documentation in the field of registration of the state tax service in the Unified State Register of Real Estate Objects is noted. It is emphasized that the lack of approaches to the consideration of urban green spaces as independent cadastral objects entails numerous violations in the field of environmental and environmental legislation of localities. A solution to this problem is proposed, which consists in mandatory accounting of cadastral data on the land plot under the state tax service when maintaining the state tax service monitoring database. The evaluation scale for a comprehensive assessment of the state of the urban green spaces, a preliminary example of the algorithm for setting the urban green spaces on cadastral registration and assigning each individual cadastral number is presented.

Keywords: urban green spaces, inventory, monitoring, landscaping objects, tree inventory, state register, GIS

\section{Введение}

Проблематика рассмотрения городских зеленых насаждений (ГЗН) как неотъемлемой части земельного участка, относящегося к городской среде, заключается в невозможности призвать к ответственности лиц, причастных к причинению вреда или уничтожению зеленых насаждений [1]. ГЗН регулярно подвергаются интенсивному антропогенному воздействию, как при выполнении защитных и экологических функций, так и при урбанизации поселений (незаконные парковки, нарушения крон деревьев при контактах с уличным освещением, контактными сетями высокого напряжения) [2]. Для решения вопроса по содержанию и развитию зеленого фонда населенных пунктов необходимо создать актуализированную базу данных всех имеющихся ГЗН. Наличие достоверных сведений о количестве и состоянии ГЗН позволит также сэкономить расходы муниципального бюджета. На основании ранее опубликованного авторами исследования [3], предлагается алгоритм постановки ГЗН на кадастровый учет и внесение сведений в ЕГРН.

\section{Материалы и методы}

На данный момент установлены два способа сбора сведений о состоянии ГЗН в Российской Федерации. Первый способ заключается в инвентаризации муниципальными органами, проводимой один раз в пять лет по устаревшей методике [4, 5], вследствие чего база данных о состоянии и количестве ГЗН, зафиксированная на бумажных картах и схемах, через короткий промежуток времени становится неактуальной. Это связано с интенсивной скоростью изменения городской среды 
в современном мире. Второй способ выполняется частными организациями, предоставляющими услуги учета и инвентаризации ГЗН в виде паспортизации. А так как сплошная паспортизация деревьев требует достаточно объемного финансирования из, опять же, муниципального бюджета, такой способ вызывает осложнения и объем выполняемой работы сокращается в разы [6].

В качестве достойной альтернативы, не требующей больших вложений, нами предлагается способ инвентаризации с использованием современных доступных геоинформационных систем (ГИС) и технологий дистанционного зондирования Земли (ДЗ3), с целью получения актуальных исходных данных о состоянии зеленых насаждений и оперативной обработки новых данных [5]. Для этой цели предлагается присвоение индивидуального кадастрового номера каждому объекту «зеленой инфраструктуры».

Чтобы поставить ГЗН на кадастровый учет и внести данные в ЕГРН, в первую очередь необходимо уточнить их нормативно-правовой статус. Так как зеленые насаждения не защищены с точки зрения экологического права как самостоятельные объекты недвижимости, они являются лишь частью земельного участка с точки зрения градостроительства, чем пользуются недобросовестные граждане, различного рода конторы и даже органы местного самоуправления. Выделение в самостоятельный объект недвижимости позволит обеспечить своевременный контроль за состоянием и количеством ГЗН, а также четко обозначить ответственность за нарушения [6].

\section{Результаты и обсуждение}

В качестве исходных данных для комплексной оценки ГЗН используется актуальное состояние насаждений, оцененное по составленной авторами статьи пятибалльной шкале (рис. 1). Данная оценочная шкала является универсальной для деревьев, некоторые частные организации проводят оценку по собственной шкале как для деревьев, так и для других видов насаждений [7]. Внешнее состояние дерева оценивается по следующим показателям: многоствольность, нарушение конфигурации кроны, сухостой, кривизна или наклон ствола, болезненный вид листвы или хвои, присутствие вредителей.

Порядок интеграции для получения комплексной оценки зеленых насаждений с применением общедоступных и бесплатных ДЗЗ и ГИС позволит лучше понять алгоритм постановки ГЗН на кадастровый учет (рис. 2) [2].

Чтобы выделить зеленое насаждение как самостоятельный кадастровый объект недвижимости, предлагается рассмотреть аналогию с признанием части земельного участка как самостоятельного объекта земельно-имущественных отношений и внесении о нем сведений в ЕГРН [8]. При образовании части какого-либо земельного участка, его исходные характеристики существенным образом не меняются, в ЕГРН сохраняются координаты точек границ, площадь, кадастровый номер. 

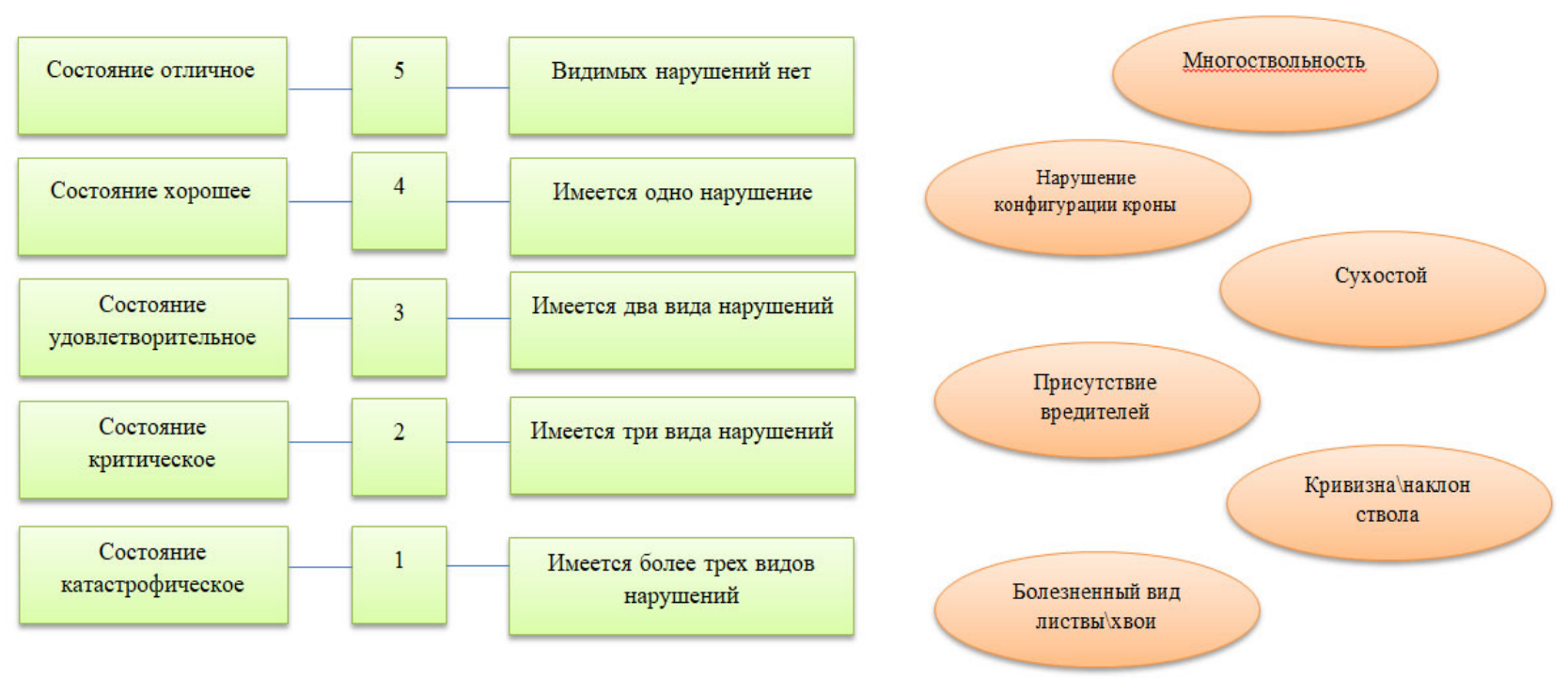

Рис. 1. Оценочная шкала внешнего состояния деревьев для комплексной оценки

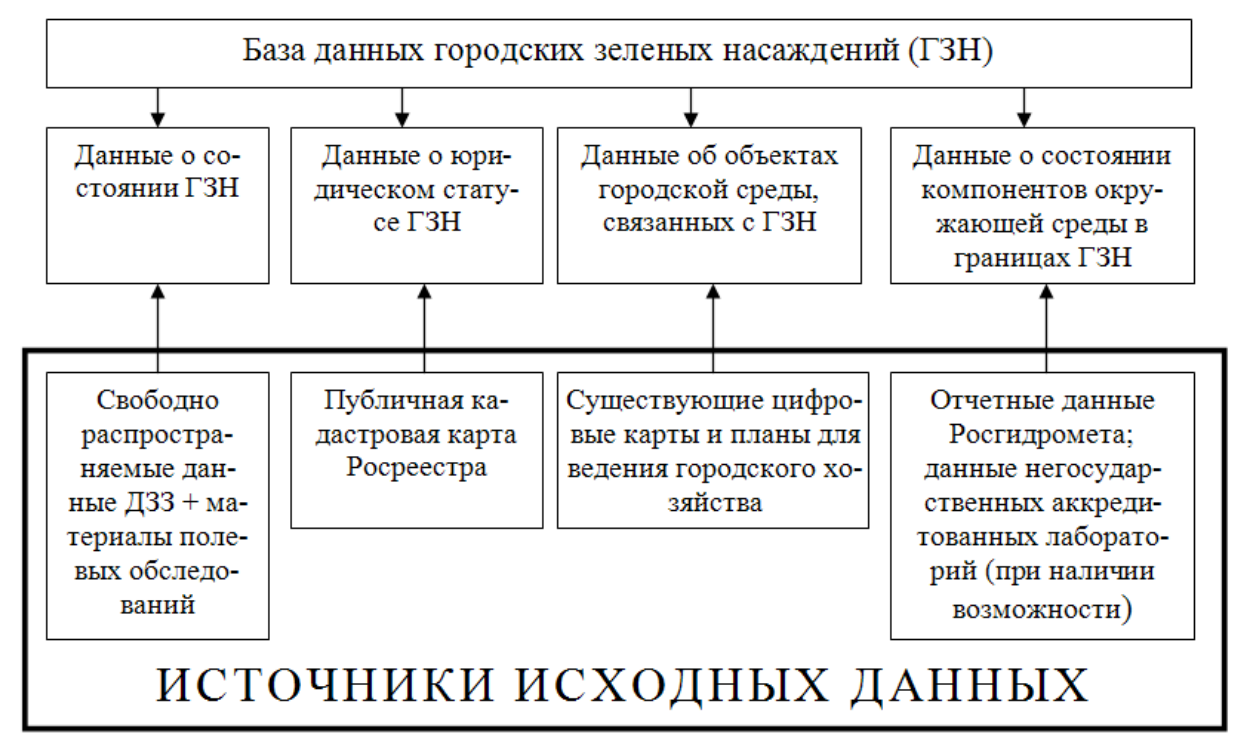

Рис. 2. Основные источники исходных данных для формирования базы данных ГЗН

Таким же образом предлагается выделять из одного земельного участка часть, на которой находятся зеленые насаждения [9]. Так как в настоящее время выделять каждое насаждение является сложной задачей как в процессе работы, так и в применении методики в будущем, рационально выделять только часть земельного участка и обеспечить нерушимость границ объектами инфраструктуры города, например несанкционированными парковками. Это позволит заложить основы для подеревного учета органами местного управления городским зеленым хозяйством, алгоритм которого будет представлен далее. Кадастровый номер выделенной части земельного участка, как самостоятельного объ- 
екта недвижимости, будет производным от кадастрового номера исходного участка, а в будущем индивидуальный кадастровый номер насаждения будет производным также от части участка.

Основываясь на методике инвентаризации зеленых насаждений с применением технологий ДЗ3 и ГИС, разработанной на кафедре экологии и природопользования Сибирского государственного университета геосистем и технологий $[10,11]$, а также данных публичной кадастровой карты (ПКК) Росреестра и методике постановки земельного участка на кадастровый учет, предлагается следующий алгоритм постановки ГЗН на кадастровый учет:

1. Камеральная дешифровка участка работ с применением предложенной методики;

2. Полевая дешифровка для уточнения информации об актуальном состоянии и количестве зеленых насаждений (при условии, если данные ДЗЗ не обновлялись больше одного календарного года);

3. Обработка полученных данных в программном обеспечении (например, MapInfo Professional);

4. Оценка состояния зеленых насаждений по разработанной 5-бальной шкале, которую предлагается установить как единую во избежание расхождения собранных данных в ЕГРН;

5. С учетом данных ПКК, присваивание индивидуального кадастрового номера, производного от участка, на котором находится зеленое насаждение;

6. Оформление конечного пакета документов и постановка ГЗН на кадастровый учет.

\section{Заключение}

Мониторинг ГЗН в г. Новосибирск осуществляет муниципальный орган городского хозяйства «Горзеленхоз» [12]. Предложенная методика постановки части земельного участка, на котором находятся ГЗН, позволит выполнять работу по мониторингу насаждений более оперативно и поможет обеспечить своевременный уход деревьям. Решение проблемы рассмотрения городских зеленых насаждений $(Г З Н)$ как неотъемлемой части земельного участка, относящегося к городской среде, компенсируется внесением данных в базу данных ГЗН. В связи с тем, что границы подкатегории зеленой инфраструктуры, которые можно детальнее посмотреть на ПКК, регулярно нарушаются точечной застройкой, встает вопрос законодательного регулирования, что является предметом дальнейших исследований.

\section{БИБЛИОГРАФИЧЕСКИЙ СПИСОК}

1. Муллаярова П. И., Николаева О. Н., Трубина Л. К. Геоэкологическая оценка и картографирование состояния озелененных территорий специального назначения // Вестник СГУГиТ. - 2018. - Т. 23, № 4. - С. 262-274.

2. Стефанский Я. В., Вараксин Г. С., Савицкая, С. С. Проблемы оформления прав на объекты внешнего благоустройства // Вестник Красноярского государственного аграрного университета. - 2013. - №. 4. - С. 148-150.

3. Николаева О. Н., Трубина Л. К., Васильева Е.А. Актуальность учета сведений ЕГРН при инвентаризации и мониторинге городских зеленых насаждений // ИнтерЭкспо Гео- 
Сибирь 2020: сб. материалов Междунар. научн. конф. «Дистанционные методы зондирования Земли и фотограмметрия, мониторинг окружающей среды, геоэкология». Т. 4. - Ч. 2. Новосибирск: СГУГиТ, 2020. - С. 11-18.

4. Методика инвентаризации городских зеленых насаждений» М. 1997. [Электронный pecypc] / - Электрон.дан. - 2020. - Режим доступа: http://gostrf.com/ - Загл. с экрана.

5. Муллаярова П. И. О необходимости совершенствования методики инвентаризации городских зеленых насаждений // ИнтерЭкспо Гео-Сибирь 2017: сб. материалов Междунар. научн. конф. «Дистанционные методы зондирования Земли и фотограмметрия, мониторинг окружающей среды, геоэкология». - 2020. - Т. 4, № 2. - С. 180-185.

6. Максименко Л. А., Дудинова О. С. К вопросу технического и кадастрового учет объектов «зеленой инфраструктуры» // Интерэкспо Гео-Сибирь. - 2019. - Т.3. - Ч.2. - С. 251-258.

7. Кулакова, С. А. (2012). Оценка состояния зеленых насаждений города. Географический вестник, (4 (23)), 59-66.

8. Zakonvl [Электронный ресурс] / отдел «Статьи» - Электрон.дан. - 2020. - Режим доступа: https://zakonvl.ru/.

9. Васильева Е.А., Николаева О.Н. Инвентаризация озелененных территорий общего назначения с использованием общедоступных данных дистанционного зондирования Земли // Экология и безопасность в техносфере: современные проблемы и пути решения. Сборник трудов Всероссийской научно-практической конференции молодых ученых, аспирантов и студентов. - 2020. - С. 3-5.

10. Васильева Е.А., Николаева О.Н. О постановке городских зеленых насаждений на кадастровый учет // Экология и безопасность в техносфере: современные проблемы и пути решения. Сборник трудов Всероссийской научно-практической конференции молодых ученых, аспирантов и студентов. - 2020. - С. 89-92.

11. Николаева О.Н., Трубина Л.К., Васильева Е.А. Геоинформационное моделирование озелененных территорий специального назначения // Интерэкспо Гео-Сибирь. - 2019. - Т. 4. № 2. - С. 47-55.

12. Городские приоритеты [Электронный ресурс] / учет и инвентаризация зеленых насаждений - Электрон.дан. - 2020. - Режим доступа: http:/green.novo-sibirsk.ru/ - Загл. с экрана.

(C) Е. А. Васильева, О. Н. Николаева, Л. К. Трубина, 2021 